\title{
Microstructural effects on stress corrosion initiation in austenitic stainless steel in PWR environments
}

DOI:

10.1007/978-3-319-67244-1_50

\section{Document Version}

Accepted author manuscript

Link to publication record in Manchester Research Explorer

\section{Citation for published version (APA):}

Tice, DR., Addepalli, V., Mottershead, K., Burke, M. G., Scenini, F., Lozano-Perez, S., \& Pimentel, G. (2017). Microstructural effects on stress corrosion initiation in austenitic stainless steel in PWR environments. In 18th International Conference on Environmental Degradation in Nuclear Power Systems https://doi.org/10.1007/978-3319-67244-1_50

\section{Published in:}

18th International Conference on Environmental Degradation in Nuclear Power Systems

\section{Citing this paper}

Please note that where the full-text provided on Manchester Research Explorer is the Author Accepted Manuscript or Proof version this may differ from the final Published version. If citing, it is advised that you check and use the publisher's definitive version.

\section{General rights}

Copyright and moral rights for the publications made accessible in the Research Explorer are retained by the authors and/or other copyright owners and it is a condition of accessing publications that users recognise and abide by the legal requirements associated with these rights.

\section{Takedown policy}

If you believe that this document breaches copyright please refer to the University of Manchester's Takedown Procedures [http://man.ac.uk/04Y6Bo] or contact uml.scholarlycommunications@manchester.ac.uk providing relevant details, so we can investigate your claim.

\section{OPEN ACCESS}




\title{
Microstructural effects on stress corrosion initiation in austenitic stainless steel in PWR environments
}

\author{
D.R. Tice, Amec Foster Wheeler, david.tice@amecfw.com \\ V. Addepalli, Amec Foster Wheeler, venugopal.addepalli@amecfw.com \\ K.J. Mottershead, Amec Foster Wheeler, kevin.mottershead@amecfw.com \\ M.G. Burke, The University of Manchester, M.G.Burke@manchester.ac.uk \\ F. Scenini, The University of Manchester, fabio.scenini@manchester.ac.uk \\ S. Lozano-Perez, University of Oxford, sergio.lozano-perez@materials.ox.ac.uk \\ G. Pimentel, University of Oxford, gemma.pimentel@materials.ox.ac.uk
}

\begin{abstract}
Although service experience of austenitic stainless steels exposed to PWR primary coolant has been good, stress corrosion crack propagation has been observed in laboratory tests in the presence of $\geq 15 \%$ cold work. Data on crack initiation are much more limited and this study therefore aims to improve the understanding of the conditions under which crack initiation and subsequent development of stress corrosion cracking might be possible. Testing was performed on two heats of Type 304/304L stainless steel under slow strain rate tensile loading. A range of analytical techniques were used to characterize the resultant precursor features and cracking, and digital image correlation before and after testing was also used to evaluation the influence of localized deformation on SCC. The results indicate that crack initiation can occur in austenitic stainless steels exposed to good quality primary coolant under dynamic straining conditions; additional testing underway under more plant-representative conditions will be reported later. Significant influences of steel microstructure on crack initiation susceptibility were observed.
\end{abstract}

\section{Keywords}

Stress corrosion cracking, SCC, Stainless steel, PWR, LWR, Initiation, Crack growth

\section{Introduction}

In the primary circuit of pressurized water reactor (PWR) plants, stress corrosion cracking (SCC) of nickelbased alloys (mainly Alloy 600 and weld metals of similar composition such as Alloys 182 and 82) has been the main cause of in-service component degradation [1]. In contrast, Type 300 series stainless steels have generally performed well, with only a relatively small number of failures due to SCC. Evaluation of field experience of austenitic stainless steels in PWRs [2,3,4] confirmed that the majority of incidences of SCC in austenitic stainless steels in high-temperature PWR primary water occurred in occluded regions in the plant, where water quality can differ significantly from that of free flowing bulk chemistry, including the presence of trapped oxygen and, in some cases, anionic impurities.

However, after long-term PWR plant operation, a few instances of SCC have been reported in locations exposed to free-flowing, nominally good quality primary water chemistry. All these instances appear to be associated with relatively high levels of surface and/or bulk cold work [5]. Stainless steels are generally used in the solution annealed and quenched condition and there are restrictions on the amount of deformation allowed during component manufacture and assembly. Nevertheless, deformation cannot always be totally avoided, and can be introduced by processes such as machining, local grinding, weld-induced shrinkage, and bending or straightening during installation.

Laboratory studies on austenitic stainless steels in PWR primary coolant environments have shown that propagation of an existing crack by stress corrosion cracking can occur if the material has been subjected to cold work to a level of about $15 \%$ or greater $[6,7,8,9]$. Crack growth rates can be high under some conditions, with rates of several millimetres per year having been measured for $20 \%$ cold work and loading normal to the cold working direction [7]. Despite these observations from crack growth tests, the good plant experience of stainless steels exposed to primary coolant suggests that crack initiation is difficult under plant loading conditions [10]. The work described in this paper is part of an ongoing collaborative study between Amec Foster Wheeler and the Universities of Manchester and Oxford which is aimed at improving understanding of the conditions under which crack initiation and subsequent development of stress corrosion cracking of stainless steels in PWR 
primary coolant might be possible. The current paper focuses on the influence of material microstructure on SCC initiation.

\section{Materials}

Testing has been performed on two heats of Type 304/304L stainless steel, of chemical compositions shown in Table 1. Heat A was Type 304 and therefore had a much higher carbon content than heat B (304L). The nickel content was substantially higher in heat A, whereas heat B contained much more molybdenum. The microstructures of the materials are illustrated in Figure 1. Heat A has a rather high average grain size of $135 \mu \mathrm{m}$, nearly 4 times as large as heat $\mathrm{B}(35 \mu \mathrm{m})$.

Table 1: Chemical compositions of tested materials (wt.\%)

\begin{tabular}{|l|l|l|l|l|l|l|l|l|l|l|}
\hline Heat & Material & $\mathbf{C r}$ & $\mathbf{N i}$ & $\mathbf{C}$ & $\mathbf{M n}$ & $\mathbf{M o}$ & $\mathbf{S i}$ & $\mathbf{S}$ & $\mathbf{P}$ & $\mathbf{F e}$ \\
\hline A & 304 & 18.42 & 9.75 & 0.056 & 1.52 & 0.01 & 0.52 & 0.001 & 0.025 & balance \\
\hline B & $304 \mathrm{~L}$ & 18.34 & 7.93 & 0.029 & 1.86 & 0.33 & 0.36 & 0.004 & 0.023 & balance \\
\hline
\end{tabular}

As a result of the higher nickel content, heat B contained substantially greater $\delta$-ferrite, approximately $5 \%$, compared to $<0.5 \%$ in heat A. The $\delta$-ferrite is clearly visible in Figure 1 b. However, there was considerable variability of the microstructure in heat $\mathrm{B}$ which resulted in optically distinct banding of surfaces prepared using certain polishing conditions, between 4000 grit abrading and $1 \mu \mathrm{m}$ diamond polishing. The banding appeared to be associated with variations in the distribution of $\delta$-ferrite. Figure 2 shows a region which includes both low and high $\delta$-ferrite bands, identified using electron-back-scattered diffraction (EBSD) in the lower figure. A scan using energy-dispersive X-ray spectroscopy (EDS) across this region showed elevated levels of nickel and manganese in the low $\delta$-ferrite band, Figure 2. This band also appeared to contain a significantly higher level of second phase inclusions than in regions of higher $\delta$-ferrite. These inclusions showed substantial variability in composition, including manganese sulphide, aluminium oxide and titanium-rich species; some examples of these inclusions are shown in Figure 3.

All tests were performed on material which had been subjected to either cold or warm working to a thickness reduction of approximately $20 \%$. The working conditions differed between the two materials. Heat A was unidirectionally cold rolled at ambient temperature. The $20 \%$ reduction in thickness was achieved by four rolling passes, each producing a reduction of $2 \mathrm{~mm}$. Both compact tension, $\mathrm{C}(\mathrm{T})$, specimens and cylindrical tensile specimens were machined from this cold worked material, with the $C(T)$ specimens machined in the $S$-L orientation and the tensile specimens oriented normal to the direction of thickness reduction. In both cases, therefore, crack propagation is expected to occur normal to the loading direction and along the rolling direction. Results of crack growth testing have been reported previously, producing crack growth rates for $20 \%$ cold work of $\sim 2 \times 10^{-11} \mathrm{~m} \mathrm{~s}^{-1}$ on several specimens at a stress intensity factor $(\mathrm{K})$ of $30 \mathrm{MPa} \sqrt{\mathrm{m} \mathrm{[}}[7]^{1}$.

Test material B was tested in a warm forged condition in order to provide a closer simulation of a weld heat affected zone (HAZ) and minimize formation of martensite. The material was oven heated to approximately $400^{\circ} \mathrm{C}$ and placed in a 1000 tonne press. A $21 \%$ thickness reduction was achieved in three presses, each of which was applied for approximately 3 seconds followed by a further 30 seconds hold to increase the applied load for the next stage. It is estimated that the working temperature of the material would have ranged between about $360^{\circ} \mathrm{C}$ for the first press to $200^{\circ} \mathrm{C}$ for the third.

Tensile testing and hardness measurements were carried out on the cold and warm-worked materials. Despite the different material compositions and working procedures, the mechanical properties were quite similar, showing ultimate tensile strength values at $300^{\circ} \mathrm{C}$ of $630 \mathrm{MPa}$ for heat $\mathrm{A}$ and $610 \mathrm{MPa}$ for heat $\mathrm{B}$, and hardness values $\left(\mathrm{Hv}_{30}\right)$ in the gauge length regions of the test specimens of 250-300 (A) and 260-280 (B).

\footnotetext{
${ }^{1}$ Note that the material referred to as heat $\mathrm{A}$ in this paper is designated heat $\mathrm{H}$ in reference 7
} 


\section{Experimental}

SCC initiation test specimen geometries differed between the two materials. All tests on heat A were performed under slow strain rate loading conditions on round tensile specimens with a parallel gauge length of $11 \mathrm{~mm}$ and diameter of $3 \mathrm{~mm}$, Figure 4a. Slow strain rate testing on heat B was performed using flat tensile (dog-bone) pin loaded specimens; the parallel gauge length was $12 \mathrm{~mm}$, the gauge width $3.5 \mathrm{~mm}$ and the specimen thickness $1 \mathrm{~mm}$, Figure $4 \mathrm{~b}$. Testing on heat B is also being performed under constant load and loading conditions more relevant to plant; this phase of testing will be reported in a later paper.

A range of surface conditions have been studied. Heat A specimens were sequentially grit polished down to 2500 grit SiC paper. For each specimen prior to testing, a flat area was created along the entire length of the specimen gauge section, which measured approximately $1 \mathrm{~mm}$ in width. To achieve this, material was gently removed from the specimen using 2500 grit silicon carbide abrasive paper. Subsequently the flat area was polished using $3 \mu \mathrm{m}$ and $1 \mu \mathrm{m}$ diamond suspension and $60 \mathrm{~nm}$ colloidal silica (OPS). Throughout all stages care was taken to ensure that an even amount of material was removed along the entire length of the specimen to prevent the introduction of a notched region which might cause premature necking of the specimen during straining. Microstructural data were subsequently collected from part of the polished region of each specimen by EBSD; scans were located towards the centre of the gauge length and covered an area of up to $5 \mathrm{~mm}^{2}$.

Most of the flat specimens from heat B were abraded on both sides with 600 grit SiC paper. One side was then polished further through sequential grit grades down to 4000 grit, followed by OPS polishing, similar to the local region of the Heat A specimens.

The test environment for all tests was simulated primary PWR coolant with 2ppm lithium as lithium hydroxide and 30 - $40 \mathrm{cc}$ hydrogen $/ \mathrm{kg}$ water (at STP). All slow strain rate (SSR) tests were performed in continuously refreshed autoclaves at a water temperature of $300^{\circ} \mathrm{C}$. The autoclave for the tests on the heat A material was stainless steel and the testing was carried out at Amec Foster Wheeler. Slow strain rate testing on heat B was performed in a Hasteloy C-276 autoclave at the University of Manchester.

Microstructural characterisation of the pre- and post-test specimens was performed using optical metallography and a field emission gun (FEG) scanning electron microscope equipped with an Oxford Instruments AZTEC electron back scatter diffraction (EBSD) system. In addition, metallographically polished cross-section specimens were evaluated using backscatter electron imaging in order to reveal the deformation and grain structures. Cracks in selected samples were cross-sectioned using a Zeiss Cross-Beam focused ion beam (FIB) scanning electron microscope (SEM) in order to assess the extent of the surface oxide and the depth and nature of the cracks. Some samples were also examined using other techniques, including analytical transmission electron microscopy (TEM); details are provided in another paper [12].

\section{Results}

Slow strain rate tests were performed in two stages. Initially, specimens were strained at a strain rate of $10^{-7} \mathrm{~s}^{-1}$ (for heat A tests) or $10^{-6} \mathrm{~s}^{-1}$ (for heat B) to a stress just below the yield stress. The strain rate was then reduced to a value between $1 \times 10^{-8} \mathrm{~s}^{-1}$ and $2.5 \times 10^{-8} \mathrm{~s}^{-1}$. Tests were usually interrupted before failure had occurred, at between approximately 1.5 and $6 \%$ plastic strain. A summary of the tests described in this paper is provided in Table 2. Additional testing and related microstructural characterisation carried out using alternative specimens or techniques are described in two other papers at this conference [12, 13]. 
Table 2: Summary of slow strain rate tests

\begin{tabular}{|c|c|c|c|c|c|c|}
\hline Heat & $\begin{array}{c}\text { Test } \\
\text { number }\end{array}$ & $\begin{array}{c}\text { Strain rate } \\
\text { below yield } \\
\left(\mathbf{s}^{-\mathbf{1}}\right)\end{array}$ & $\begin{array}{c}\text { Strain } \\
\text { rate after } \\
\text { yield }\left(\mathbf{s}^{-\mathbf{1}}\right)\end{array}$ & $\begin{array}{c}\text { Test } \\
\text { duration } \\
(\text { hours })\end{array}$ & Pre-strain & $\begin{array}{c}\text { Total } \\
\text { strain at } \\
\text { end of test }\end{array}$ \\
\hline A & SSRT-A1 & $1 \times 10^{-7}$ & $1 \times 10^{-8}$ & 920 & - & $3.6 \%$ \\
\hline A & SSRT-A2 & $1 \times 10^{-7}$ & $1 \times 10^{-8}$ & 765 & - & $2.9 \%$ \\
\hline A & SSRT-A3 & $1 \times 10^{-7}$ & $1 \times 10^{-8}$ & 480 & - & $2.0 \%$ \\
\hline A & SSRT-A4 & $1 \times 10^{-7}$ & $1 \times 10^{-8}$ & 350 & - & $1.7 \%$ \\
\hline & & & & & - & \\
\hline B & SSRT-B1 & $1 \times 10^{-6}$ & $2.5 \times 10^{-8}$ & 500 & - & $5 \%$ \\
\hline B & SSRT-B2 & $1 \times 10^{-6}$ & $1 \times 10^{-8}$ & 900 & - & $3 \%$ \\
\hline B & SSRT-B4a & $1 \times 10^{-6}$ & $1 \times 10^{-8}$ & 525 & $1 \%$ & $4 \%$ \\
\hline B & SSRT-B4b & $\begin{array}{c}\text { Re-expose } \\
\text { B4a specimen }\end{array}$ & $2.5 \times 10^{-8}$ & +340 & $\mathrm{n} / \mathrm{a}$ & $6 \%$ \\
\hline
\end{tabular}

\subsection{Heat A}

Slow strain rate testing produced stress corrosion cracking in all four tested specimens. In tests A1 and A2, which were continued to 3.6 and $2.9 \%$ strain, respectively, significant intergranular (IG) cracking was observed which extended to several hundred micrometres; this represents several grain boundaries in this material which had a relatively large grain size. An example of such a crack is shown in Figure 5a. The surface condition was found to influence the susceptibility to cracking in that the frequency of cracking, and the crack lengths, were reduced within the OPS polished section of the specimen. Figure 5b shows typical cracking in the OPS polished region for one of the longer duration tests. The extent of cracking was significantly reduced in the shorter duration tests. Only two IG cracks were identified in the OPS polished region on the specimen from test A3 which was stopped at $2 \%$ strain and only a single IG crack was found in test A4 (1.7\% strain). These cracks were limited to only a small number of grain boundaries. Figure 6 shows a section of one of these shorter cracks. This crack shows a degree of crack branching at a triple junction and it is noteworthy that the greater degree of crack propagation has occurred where there is a large difference in the deformation features between adjacent grains. An analysis of cracking in the region characterised by EBSD prior to test has been reported previously by Nouraei et al [11] Images of two cracks from test A3 are shown in Figure 7. These show more clearly that the deformed microstructure, induced by cold working, is significantly different in grains either side of the cracked boundary.

Limited transgranular cracking was also observed for these first two, longer duration, higher strain tests, Figure 8a. These have been found to be associated with deformation bands produced during cold-rolling as can be seen in the image. Within larger intergranular cracks, secondary transgranular cracking was often observed, most likely also occurring along deformation bands, Figure $8 \mathrm{~b}$. A notable feature on the flanks of cracks was enhanced deposition of iron-rich oxide crystallites on deformation bands, Figure 9a. This suggests that iron is able to rapidly diffuse along the deformation band and locally contribute to the oxide formed at the surface. Such localisation of cracking is not usually seen on the ground specimen surface which is covered in a thick oxide: this oxide contains numerous shallow cracks, most of which do not penetrate into the metal, Figure $9 \mathrm{~b}$. Below the outer oxide, a thinner chromium rich oxide can be seen, as reported by numerous other workers. It is generally accepted that, in PWR conditions, the Cr-rich oxide forms through ingress of oxygen into the metal, whilst iron ions are rejected into solution and re-precipitate to form the outer Fe-rich outer oxide. On the ground surface, localised oxidation of deformation bands leads to penetration of the Cr-rich oxide into the substrate, although the depths of such penetrations are only around $1 \mu \mathrm{m}$, Figure $9 \mathrm{c}$.

\subsection{Heat B}

As for heat A, all specimens subjected to slow strain rate testing exhibited crack-like features. However, there were significant differences between some of the features seen on heat B compared to heat A, and not all the features for heat B were due to stress corrosion cracking. Figure 10 shows surface images of portions of the OPS polished and 600 grit ground surfaces from SSR test B2 which was terminated at $3 \%$ strain. Similar images for SSR test B1, terminated at 5\% strain are shown in Figure 11. Most of the surface crack-like features from test B2 (3\% strain) seen on the OPS surface were transgranular and very shallow; many did not penetrate 
the oxide and those that did were usually no more than $2 \mu \mathrm{m}$ deep and were associated with locally deeper oxide regions, Figure 12a. They are considered to represent rupture of shallow oxide penetrations, usually at deformation bands, due to the applied strain rather than stress corrosion cracking. However, occasionally, cracks were seen to propagate along grain boundaries after a small cracked oxide penetration intersected a grain boundary, Figure $12 \mathrm{~b}$ and $\mathrm{c}$, indicating that these features can act as precursors to SCC initiation under favourable conditions.

In the case of the specimen from test B1 which was tested to 5\% strain, a significant number of larger cracks were found, and were more numerous on the OPS surface compared to the 600 grit face. Cracks on the OPS surface also appear to be positioned in bands, as seen in Figure 11a. The reasons for this variability is not currently clear although it may relate to some variability in microstructure or composition similar to that shown in Figure 2. The cracks on the OPS polished surface usually initiated from the surface as IGSCC and propagated with intergranular morphology up to a depth of up to about $100 \mu \mathrm{m}$ deep, extending through approximately 3 grains into the depth, Figure 13a. In contrast, cracks on the 600 grit surface were usually shallower and appeared to initiate with mainly transgranular morphology within a shallow fine grained surface layer, and then transitioned to intergranular beyond this layer, similar to the crack from test B2 shown in Figure $12 \mathrm{~b}$. A number of shallow, non-propagating transgranular cracks were also observed on the OPS surface in the test B1 specimen, one of which can be seen on the left of Figure 13a.

The test conditions for SSR test B4 were similar to those for tests B1 and B2. However, prior to the autoclave exposure the sample was pre-strained to $1 \%$ at room temperature whilst being analysed with digital image correlation (DIC). The purpose of the DIC analysis was to obtain a localized area map of the strain distribution at microscopic level with the aim of correlating the strain localization with the early stages of SCC, as had been done in the tests on heat A. The specimen was then tested at a strain rate of $1 \times 10^{-8} \mathrm{~s}^{-1}$ to an additional $3 \%$ plastic strain (final strain 4\%). SEM examination of the tested sample showed a very limited degree of cracking on either face of the sample, similar to the observations in Test B2. Some local cracking around inclusions was also observed similar to that in Figure 10a. The test was restarted at a higher strain rate of $2 \times 10^{-8} \mathrm{~s}^{-1}$, with the aim to plastically deform the sample by a further $2 \%$. The additional testing was carried out for a further 340 hours and resulted in substantial surface cracking (Figure 14). The cracks were observed to form in a band of the material $\sim 1 \mathrm{~mm}$ wide which was just off the centre of the gauge length and was in the same location as the small degree of cracking observed after the first testing period. However, no significant cracking was observed in the pre-test characterised region so that it was not possible to correlate cracking with pre-test in this case. It is likely that the EBSD and DIC were carried out in a banded region more resistant to SCC similar to that on the right hand side of in Figure 11a.

On all of the heat B specimens, in addition to cracking in the austenite matrix, a number of cracks were also observed at the interface between the austenite matrix and $\delta$-ferrite, e.g. Figure $13 \mathrm{~b}$ from test B1. Further testing and characterisation is being carried out to determine whether this cracking is influenced by the high temperature water environment or whether the cracks are just a result of mechanical straining, and also to investigate further their influence on IGSCC in the austenite. A number of other features were observed related to the presence of the complex inclusions in the heat B material. During exposure, these inclusions partly dissolve, revealing surface features that, at low magnification, resemble wide aspect ratio surface cracks. Due to the imposed dynamic strain under SSR loading, the surface oxide appears to crack locally adjacent to these inclusion sites. This is most evident for the ground surface, e.g. Figures $10 \mathrm{~b}$ and $11 \mathrm{c}$, due to the thicker oxide formed on the ground surface. There is some evidence that the associated oxide cracks can extend into the metal so that these inclusions, in some instances, may act as precursors to SCC. Further discussion of the role of inclusions and $\delta-\gamma$ interface cracking are provided in other papers at this conference [12,13].

\section{Discussion}

Slow strain rate tests on both heats of $20 \%$ cold or warm worked Type 304 and 304L stainless steel have shown that intergranular stress corrosion crack initiation can occur in good quality PWR primary water under the dynamic straining conditions in these tests, which involved slow straining above yield at rates in the range 1$2.5 \times 10^{-8} \mathrm{~s}^{-1}$. The extent of cracking was closely related to the level of plastic strain introduced before testing was terminated, with the density, surface length, and depth of cracking all increasing with the level of strain. For the cold-worked heat A, IGSCC initiation was quite widespread for strains above about 3\%, whereas SCC was 
much more localised at lower strains (down to 1.7\%), extending for only 1-2 grains or around 50 $\mu$ m. In the lowest strain test A4, only one crack was found within the OPS polished and EBSD scanned area, although IGSCC was somewhat more widespread elsewhere on the specimen where the surface was 2500 grit abraded. The microstructure of the cold-worked material contained a high density of planar deformation bands, imaged using electron channelling contrast imaging in the SEM, Figure 15a. Cracking appeared to initiate preferentially on grain boundaries, with significant differences between the deformation structures in adjacent grains, especially boundaries at a high angle to the loading direction, Figure 7 . This has been attributed to localization of strain in these locations [10]. At higher strains, limited shallow cracking was also found on these deformation bands, as shown in Figure 8a, but did not appear to contribute significantly to subsequent IGSCC. Similarly, for heat B, a significant influence of applied strain on SCC susceptibility was observed. In this case, crack depths for $3 \%$ strain were significantly smaller than for heat A, with the largest crack detected on the OPS surface $(18 \mu \mathrm{m})$ being twice that for 600 grit. The majority of cracks were significantly smaller than this, however. At $5 \%$ strain, cracks ranged up to about $90 \mu \mathrm{m}$ on both surfaces, although the numbers of cracks were much greater for the OPS polished surface in almost all depth ranges.

The reasons for the apparent difference in susceptibility of the two heats are not entirely clear. The differences in specimen geometry, surface preparation and test procedure may play a role, and differences in material composition, microstructure or cold working procedure may be significant. The higher nickel content in heat A would be expected to increase stacking fault energy and hence reduce slip planarity. However, any such effect is likely to be more than offset by the use of cold working which has been shown to maximize the formation of planar deformation bands, relative to warm forging for heat B. The much larger grain size in heat A reduces the number of boundaries exposed to the environment in a given area, but reduces the obstacles to crack propagation through triple points.

The surface condition was found to influence the susceptibility to cracking, although the observations from heats $\mathrm{A}$ and $\mathrm{B}$ were not entirely consistent. For heat A, the density of cracking, and the crack lengths and depths were both lower within the OPS polished section of the specimen. Therefore, even though the alloy is significantly cold worked in the bulk, the additional damage at the surface from abrading even to a fine 2500 grit finish appears to further increase the SCC susceptibility. In contrast, in the case of heat B, larger and more numerous cracks were found on the OPS finish surface compared to the 600 grit ground face.

The 600 grit surface was found to possess a modified fine-grained outer layer up to $2 \mu \mathrm{m}$ thick which results in significant enhancement of surface oxidation compared to the OPS surface. When cracks initiate in this layer they are of transgranular morphology and appear to develop by enhanced oxidation of deformation bands which subsequently crack. The crack so created must intersect an underlying grain before crack extension by IGSCC can occur, which is a random process. In contrast, the exposed grain boundaries at the OPS surface can undergo SCC more readily. It is likely that the 2500 grit surface has a thinner modified outer layer although, in this case, it is less obvious why this should enhance SCC relative to the OPS surface. A possible explanation is that the pre-characterisation by EBSD of the OPS region on the heat A specimens resulted in a thin carbon contamination layer. There is evidence of this occurring in locally pre-characterised areas on the OPS face of heat B specimens and this has been observed to retard SCC initiation, as discussed in another paper at this conference [13].

It has been found that the surface oxidation layer is significantly thicker in the 600 grit ground versus OPS polished specimens, which is attributed to a higher oxidation rate for the fine-grained layer and increased localized deformation below this band. For long term exposure in plant, it is therefore likely that the beneficial effect of the fine-grained layer would eventually be lost by oxidation, in which case the deformed layer beneath may be detrimental compared to a smoother surface. This has potential implications for plant. The surface layer produced on the cold worked material in this study may be different for a non-cold worked annealed material condition as present in most locations in plant components. It is noted, however, that elevated levels of plastic strain are likely to be present adjacent to welds so that the present observations on cold worked material may be more directly relevant in this case.

In the context of operating PWR plant, it must be recognised that the slow strain rate test is a severe test with regard to the imposition of high levels of plastic strain, with continuous dynamic loading. In contrast, test durations are extremely short compared to plant component lifetimes. Further testing is planned under loading conditions which more closely approach those in plant. The OPS finish is also not directly applicable but has 
been used to enable investigations of the early stages of SCC initiation in the absence of surface damage layers which are usually present to some degree from component manufacturing processes.

\section{Conclusions}

1. SCC has been observed in $20 \%$ cold or warm worked Type 304/304L stainless steel in a PWR primary coolant environment at $300^{\circ} \mathrm{C}$ using slow strain rate testing at strain rates of $1-2.5 \times 10^{-8} \mathrm{~s}^{-1}$ above plastic strain levels of $2-3 \%$.

2. Initiation of SCC under these conditions requires a minimum of about 2-3\% applied plastic strain additional to the prior cold work, with the value varying somewhat between the two material heats.

3. The density, length and depth of cracking increases substantially between 2 and $5 \%$ applied plastic strain and also differs for the two material heats.

4. On an oxide-dispersion polished (OPS) surface, the majority of SCC cracks in both materials initiate on grain boundaries. For the cold-worked material, initiation occurs preferentially on grain boundaries which are intersected by deformation bands produced by cold work, which may enhance IGSCC relative to the warm-worked material.

5. On the 600 grit abraded face of the warm-worked material, crack initiation appeared to predominantly transgranular. This appeared to occur by preferential oxidation at slip bands below a fine grain surface layer produced by the surface preparation which, under slow strain rate loading, led to the formation of shallow transgranular cracks. If such cracks intersect high angle grain boundaries, cracking can develop into IGSCC.

6. Material composition and microstructure appears to play a significant role in SCC initiation:

- In Heat B, which has a high level of delta-ferrite, cracking at ferrite/austenite boundaries is also observed. The role of environment on this cracking requires further investigation, although it does appear that some of these cracks can develop into intergranular SCC in the austenite;

- The complex inclusions present in heat B appear to be capable of initiating defects which may subsequently propagate into the surface oxide. The extent to which these may extend depth-wise into the metal matrix is not well characterised.

7. Further work is needed to determine the extent to which these observations may be relevant to loading conditions in plant, for example under constant load or in the presence of small amplitude cyclic loading.

\section{References}

1. W. Bamford, "Cracking of Alloy 600 Nozzles and Welds in PWRs: a Review of Cracking Events and Repair Service Experience," Proc.12 ${ }^{\text {th }}$ International Conference on Environmental Degradation of Materials in Nuclear Power Systems - Water Reactors, Snowbird, Utah, August 2005

2. G Ilevbare, F Cattant and N Peat, "SCC of Stainless Steels under PWR Service Circuit Conditions", International PWR Materials Reliability Conference and Exhibition, 27 June -2 July 2010, Colorado Springs, CO

3. R. Hosler, S. Fyfitch1, H. Malikowski, and G. Ilevbare, "Review of Stress Corrosion Cracking of Pressure Boundary Stainless Steel in PWRs and the Need for Long-term Industry Guidance" Proc. $16^{\text {th }}$ International Conference on Environmental Degradation of Materials in Nuclear Power Systems Water Reactors, Asheville, NC, August 2013

4. J.-M Boursier et al., "Stress Corrosion Cracking of Austenitic Stainless Steel in PWR Primary Water: An Update of Metallurgical Investigations Performed on French Withdrawn Components", International Symposium Fontevraud V. 2002 
5. Materials Reliability Program: Assessment of the Current Status and Completeness of Work on Inner and Outer Diameter Stress Corrosion Cracking of Austenitic Stainless Steels in PWR Plants (MRP352), EPRI 3002000135, March 2013

6. D.R. Tice, J. W. Stairmand, H. J. Fairbrother and A. Stock, "Crack Growth Testing of Cold Worked Stainless Steel in a Simulated PWR Primary Water Environment to Assess Susceptibility to Stress Corrosion Cracking,", Proc. 13th International Conference on Environmental Degradation of Materials in Nuclear Power Systems-Water Reactors, Whistler, British Columbia, Canada, August 2007

7. S. Nouraei, D.R. Tice, K.J. Mottershead and D.M. Wright, "Effects of Thermo-mechanical treatments on deformation behaviour and IGSCC susceptibility of stainless steel in PWR, Primary Water Chemistry", Proc. $15^{\text {th }}$ International Conference on Environmental Degradation of Materials in Nuclear Power Systems - Water Reactors, Colorado Springs, August 2011

8. K. Arioka, T. Yamada, T. Terachi, G. Chiba, "Cold work and temperature dependence of stress corrosion crack growth of austenitic stainless steels in hydrogenated and oxygenated high-temperature water", Corrosion, 63 (2007), 1114-1123

9. L. Tribouilloy et al, "Stress Corrosion Cracking on Cold-worked Austenitic Stainless Steels in PWR Environment", Proc. 13th International Conference on Environmental Degradation of Materials in Nuclear Power Systems-Water Reactors, Whistler, British Columbia, Canada, August 2007

10. T. Couvant et al, "Investigations on the Mechanisms of PWSCC of Strain Hardened Austenitic Stainless Steels". Proc. 13th International Conference on Environmental Degradation of Materials in Nuclear Power Systems-Water Reactors, Whistler, British Columbia, Canada, August 2007

11. S. Nouraei and D.R. Tice“, Towards a mechanistic understanding of the influence of thermomechanical treatment on crack initiation in high temperature PWR environments", Proc. 16th International Conference on Environmental Degradation of Materials in Nuclear Power Systems-Water Reactors, Asheville, NC August 2007

12. G. Pimentel et al." High-resolution characterisation of austenitic stainless steel in PWR environments: effect of strain and surface finish on crack initiation and propagation", this conference

13. F. Scenini et al. "Mechanistic Understanding of Environmentally Assisted Fatigue Crack Growth of Austenitic Stainless Steels in PWR Environments", this conference 


\section{Figures}

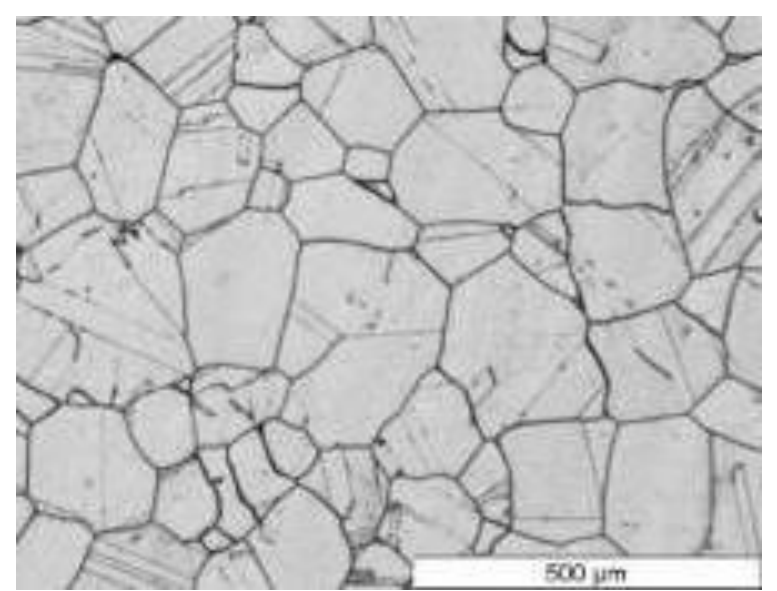

Heat A

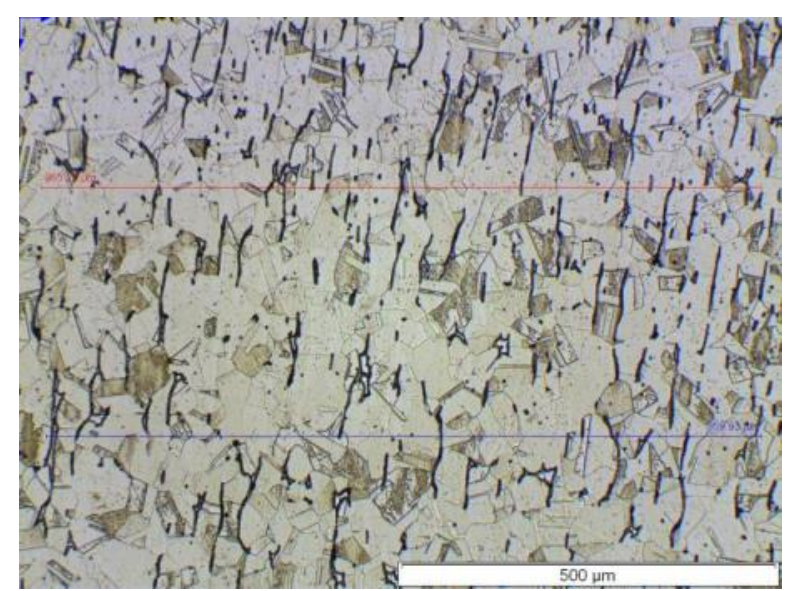

Heat B

Figure 1: Microstructures of tested materials
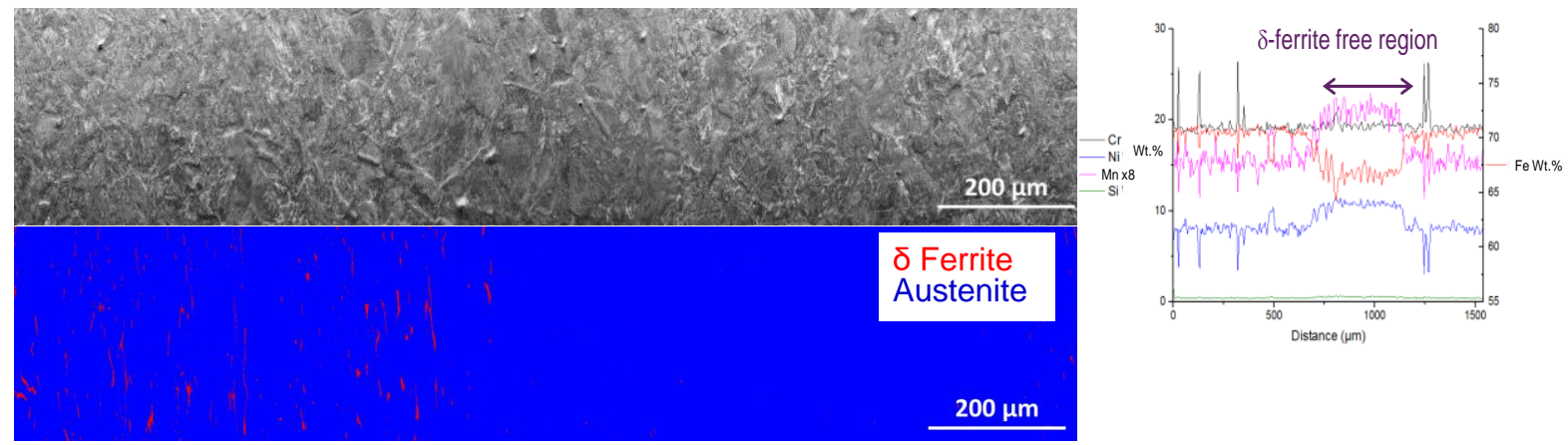

Figure 2: Regions of heat B containing low (right) and high levels of $\delta$-ferrite (left). The $\delta$-ferrite is shown in red in the EBSD image in the lower figure' The EDS scan on the right shows elevated $\mathrm{Ni}$ and $\mathrm{Mn}$ in the low $\delta$-ferrite region

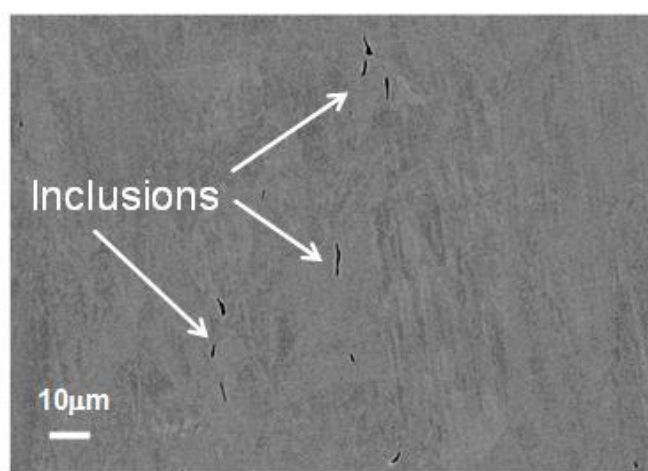

a)

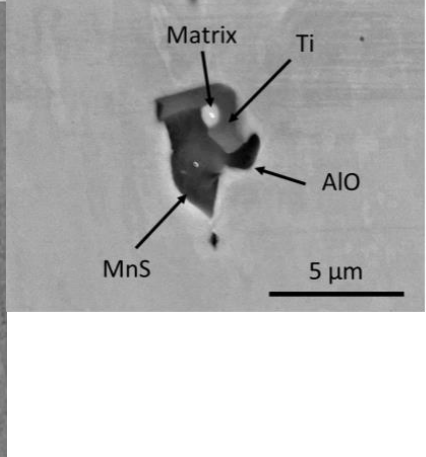

b)

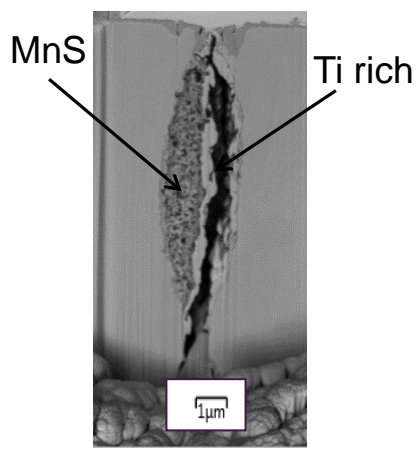

c)

Figure 3: a) Inclusions in low $\delta$-ferrite band; b) and, c) Examples of second phase inclusions 


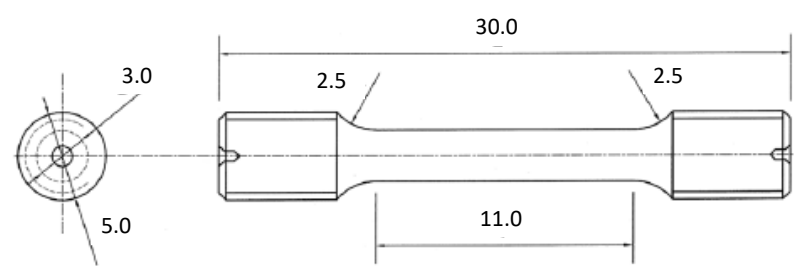

a) Heat A tests

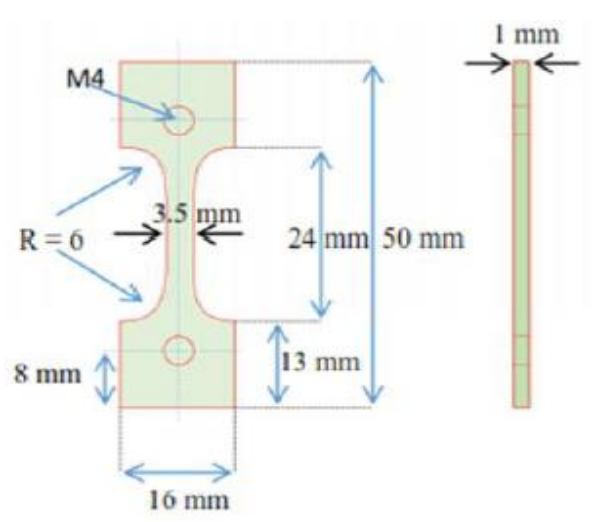

b) Heat B tests

Figure 4: Slow strain rate test specimen geometries

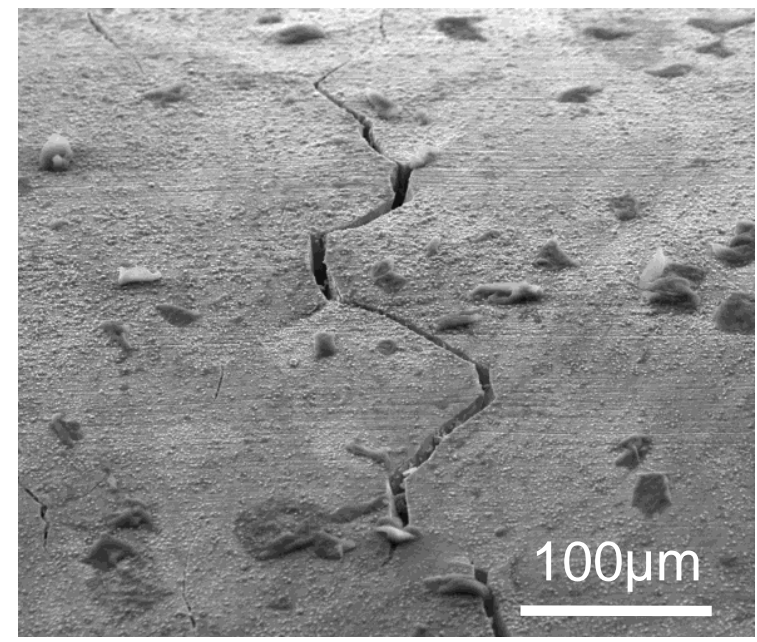

$\leftarrow$ Straining direction $\rightarrow$

a) 2500 grit polished

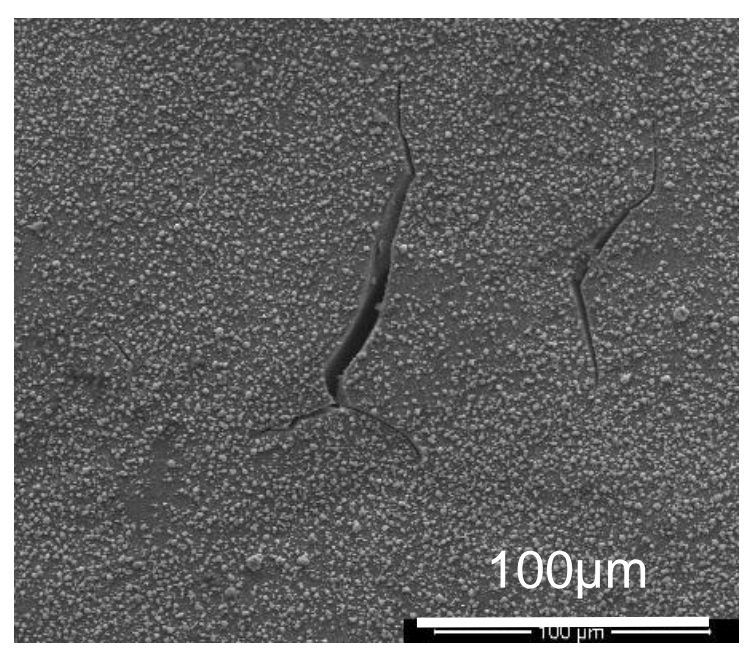

b) OPS polished

Figure 5: Intergranular cracking on ground and polished surfaces of SSRT heat A specimen

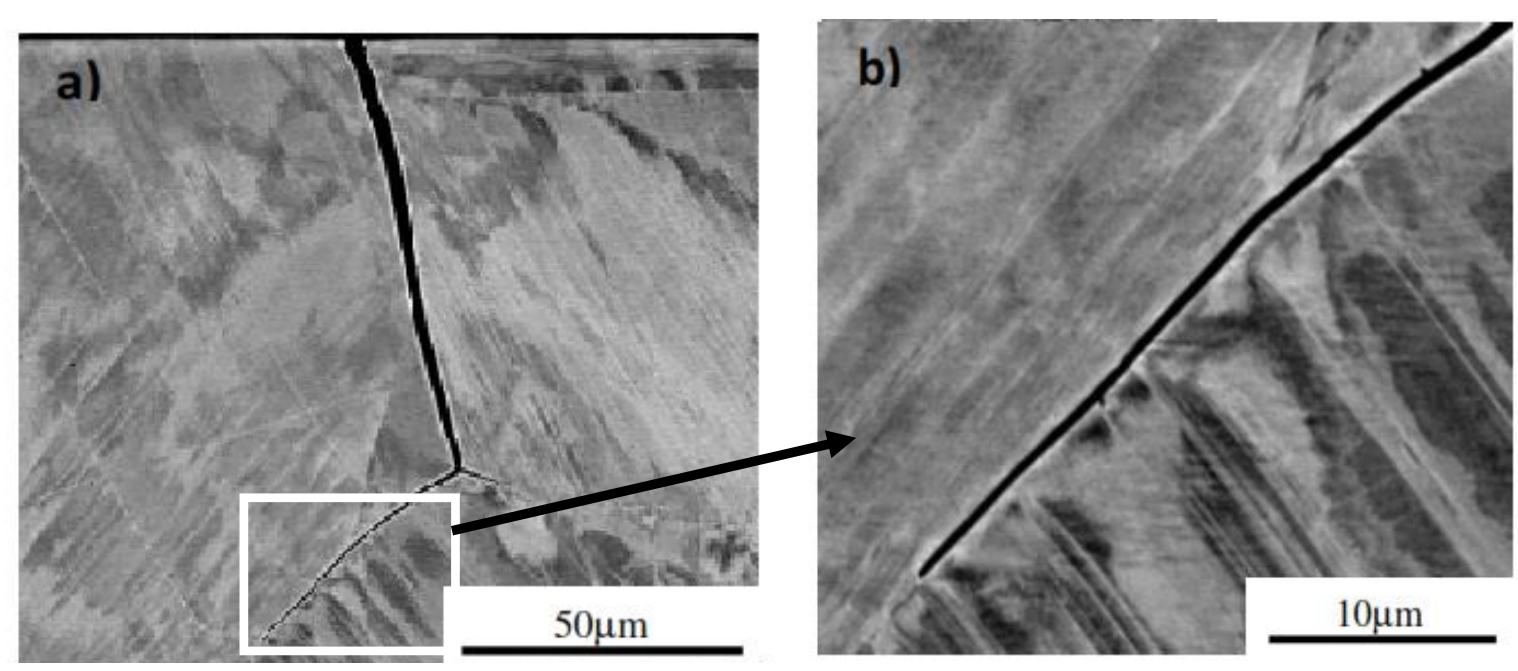

Figure 6: Cross section of intergranular crack in specimen from Test A3 


\section{CRACK 1}

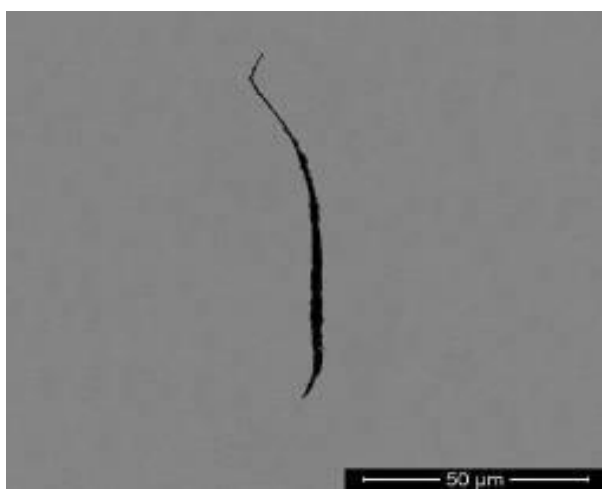

\section{CRACK 2}
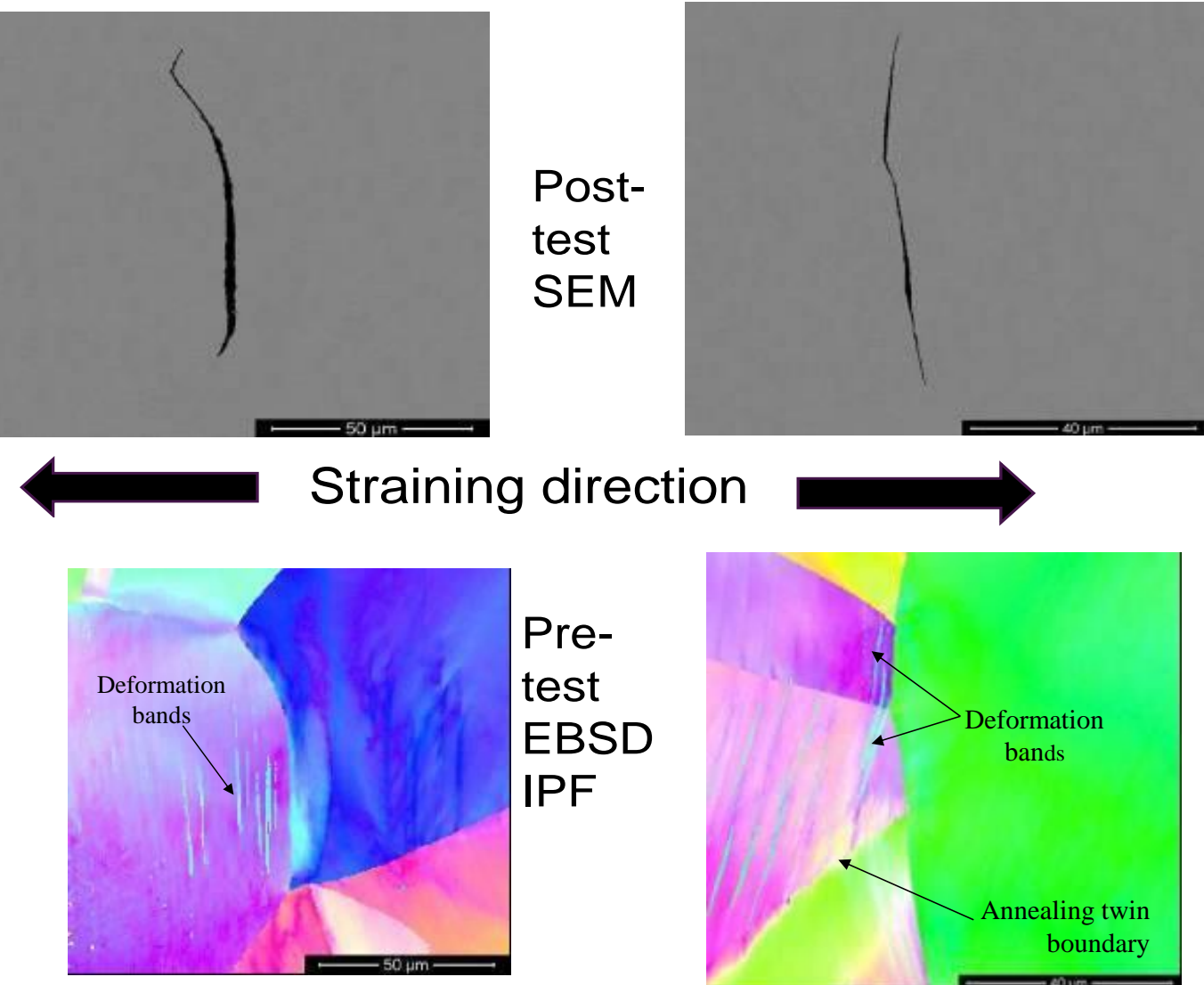

Figure 7: Cracks produced in Test A3 in the EBSD characterised region of Test A3 (upper images) and comparison with microstructure measured prior to test (lower images)
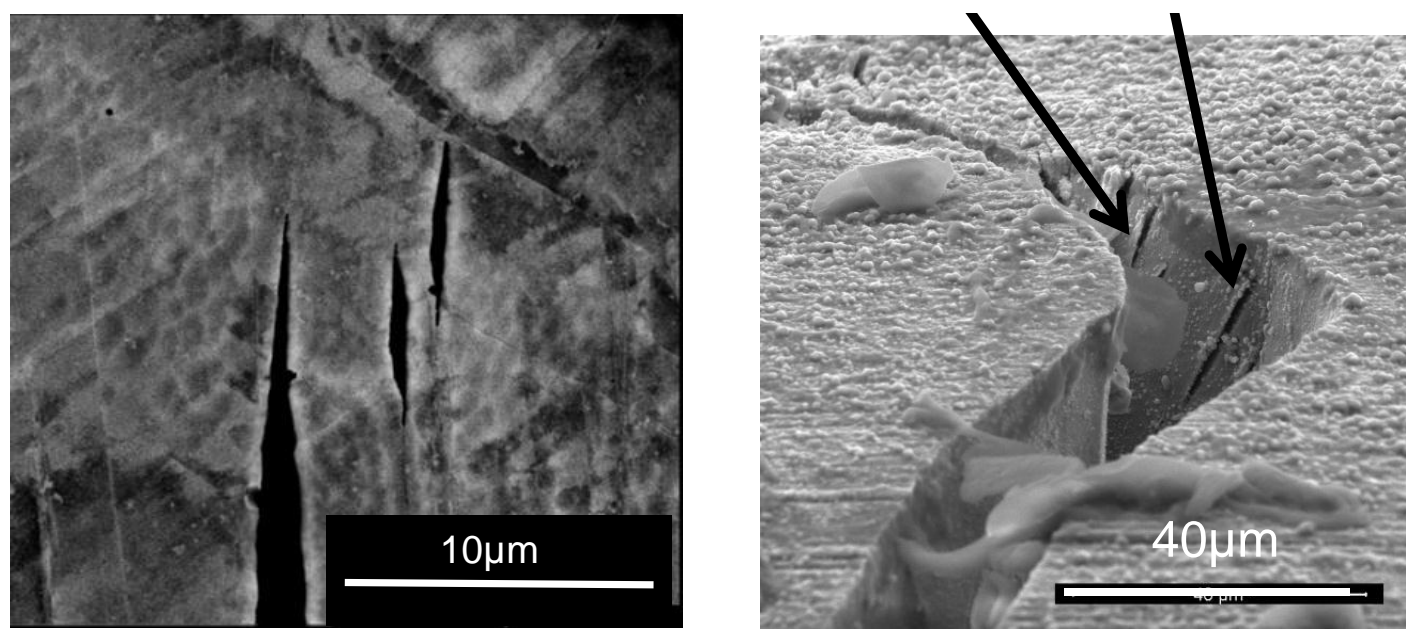

Figure 8: a) Transgranular cracking on specimen surface;

b) secondary cracking at slip bands within IG crack (arrowed) 


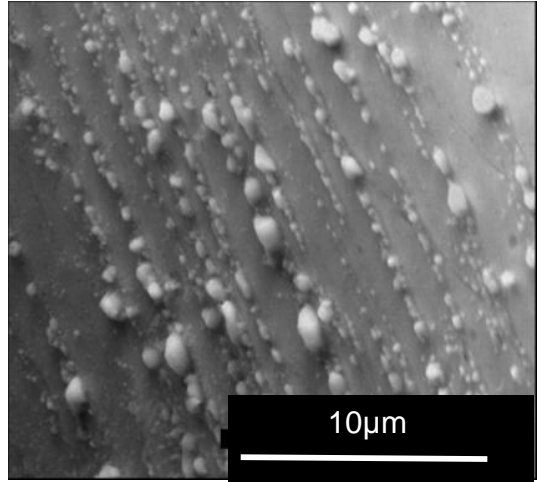

a)

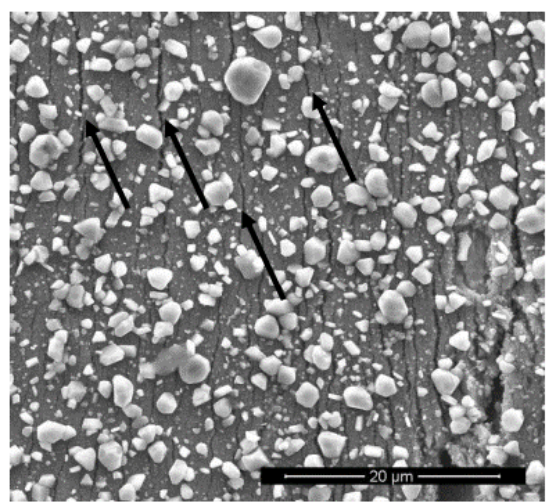

b)

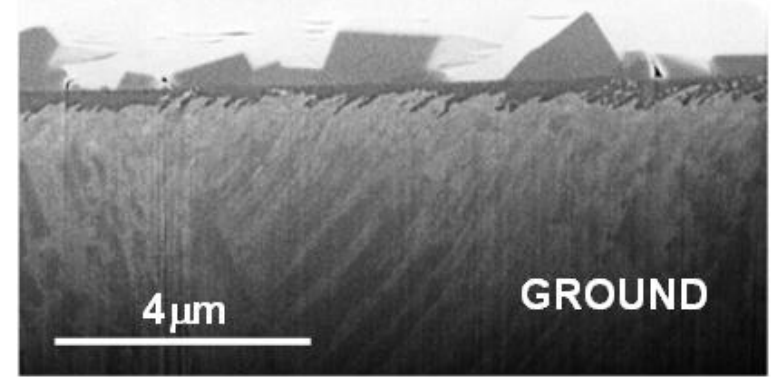

c)

Figure 9: a) Localized oxide deposition at deformation bands on crack flanks; b) Surface oxide on ground surface showing shallow cracking(arrowed); c) Localised oxidation of deformation bands on ground surface

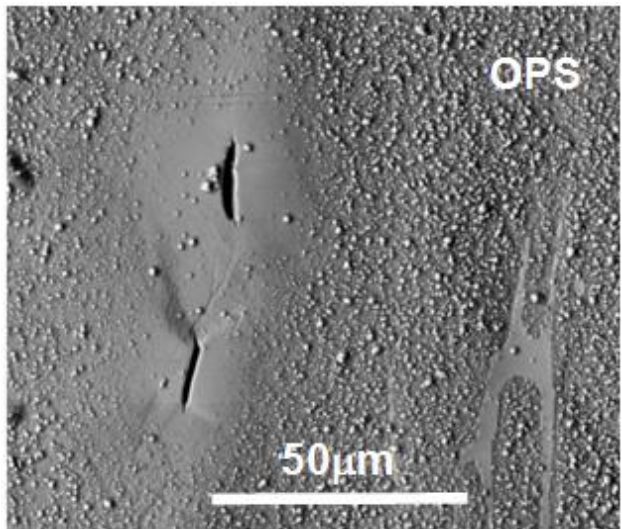

a) OPS polished

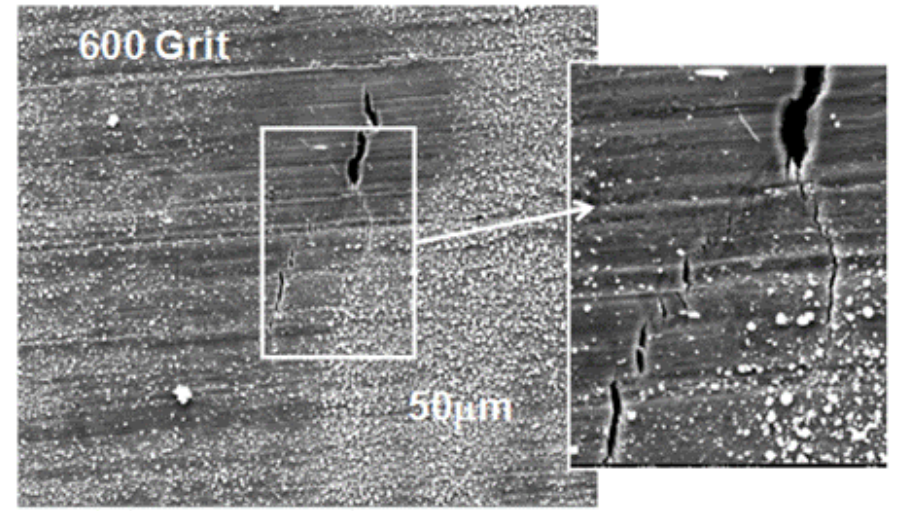

b) 600 grit ground

Figure 10: Surface images from SSR test B2, tested to $3 \%$ strain: a) dissolved inclusions on OPS surface;

b) dissolved inclusions and localised oxide cracking on ground surface 


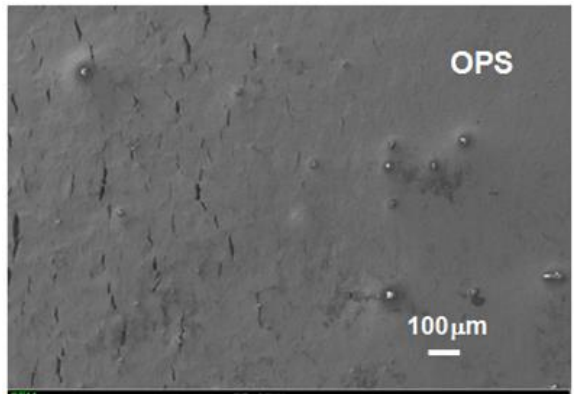

a) OPS polished

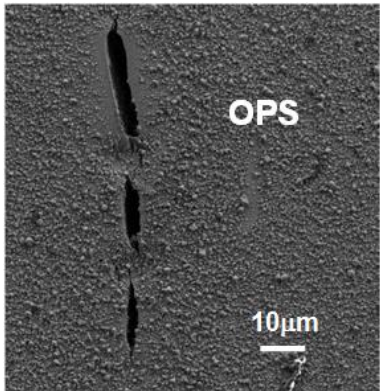

b) OPS polished

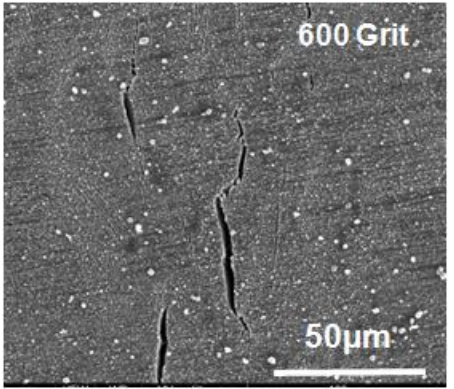

c) 600 grit ground

Figure 11: Surface images from SSR test B1, tested to 5\% strain: a) transgranular cracking on OPS surface;

b) dissolved inclusions on OPS surface; c) dissolved inclusions and localised oxide cracking on ground surface

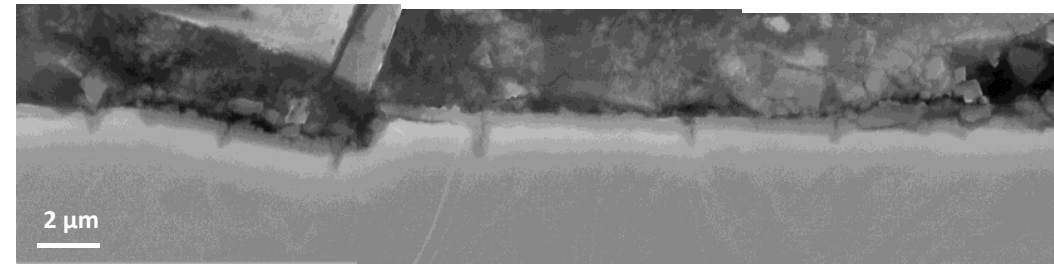

a) Shallow transgranular cracking

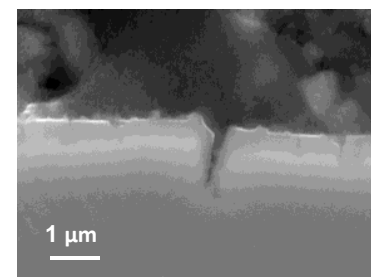

$\underline{1 \mu \mathrm{m}}$

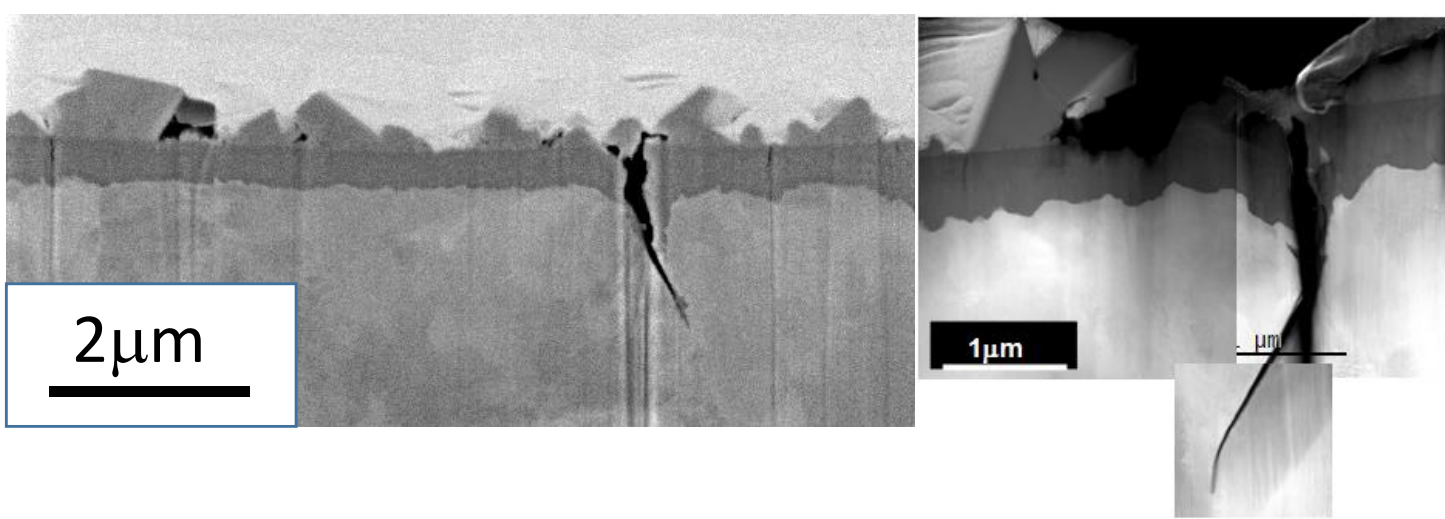

b) Transgranular cracking which subsequently propagates along a grain boundary

Figure 12: Cracking in SSR Test B2

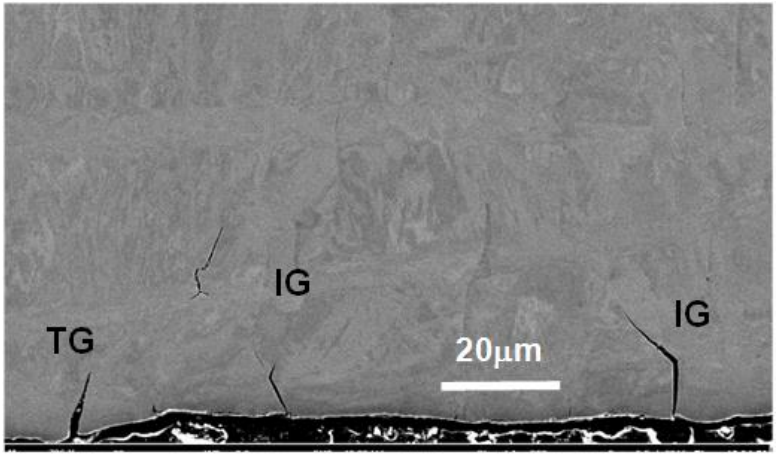

a) Intergranular (IG) and transgranular (TG) cracks

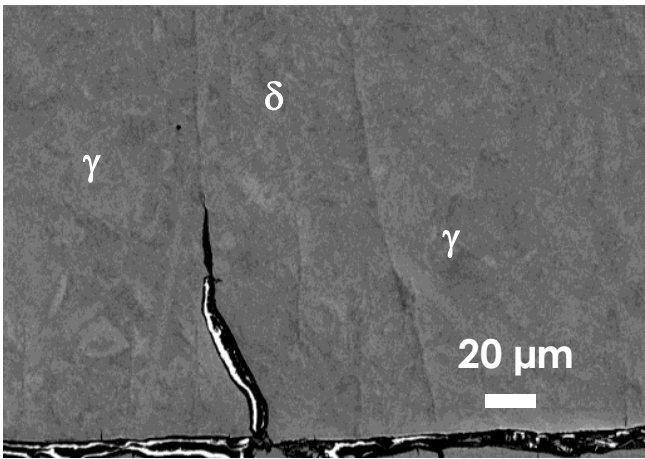

b) Cracking at $\delta$-ferrite to austenite interface

Figure 13: Specimen cross-section showing different cracking locations and morphologies for SSR test B1 tested to $5 \%$ strain 


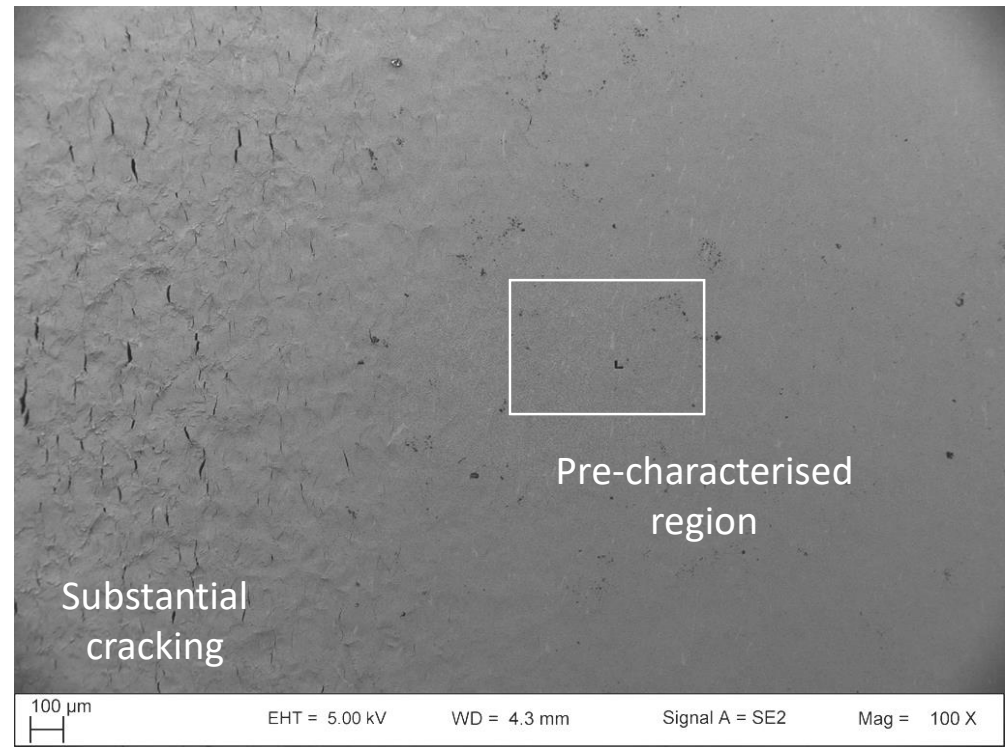

Figure 14: Surface cracking observed on the OPS surface in Test 4a

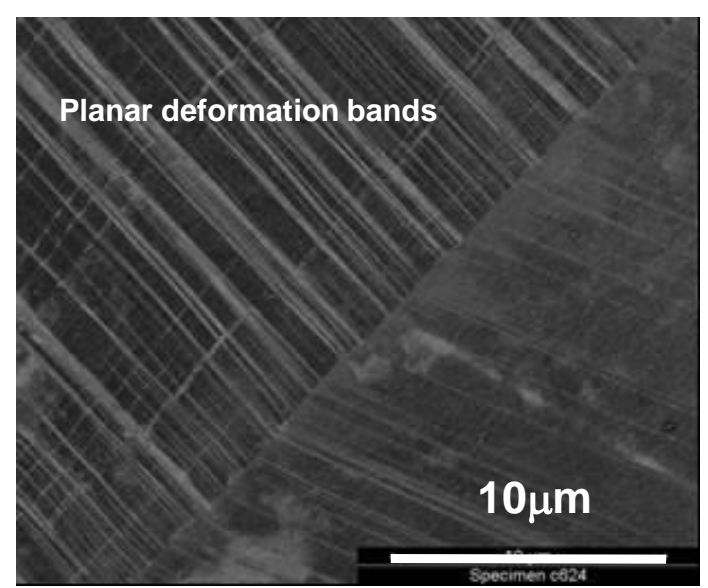

Heat A - cold rolled

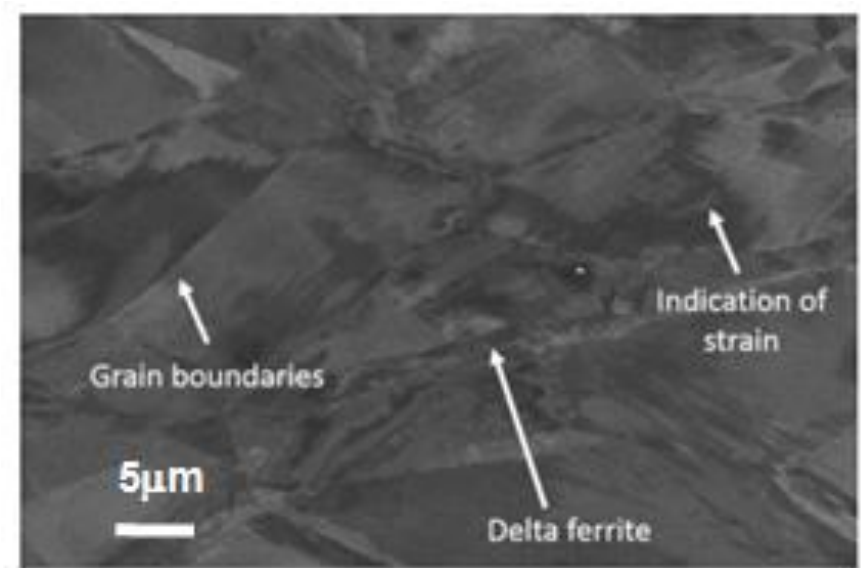

Heat B - warm forged

Figure 15: Microstructures of tested materials after cold or warm working 